\title{
Is induced abortion a risk factor in subsequent pregnancy?
}

\author{
Manfred Voigt ${ }^{1, *}$, Wolfgang Henrich ${ }^{2}$, Marek \\ Zygmunt $^{1}$, Klaus Friese ${ }^{3}$, Sebastian Straube ${ }^{4}$ \\ and Volker Briese ${ }^{5}$ \\ ${ }_{1}^{1}$ Department of Obstetrics and Gynecology, Ernst- \\ Moritz-Arndt-University of Greifswald, Germany \\ 2 Department of Obstetrics, Charité, Campus Virchow \\ Klinikum, Berlin, Germany \\ ${ }^{3}$ Department of Obstetrics and Gynecology, Ludwig- \\ Maximilians-University Munich, Germany \\ ${ }^{4}$ Horton General Hospital, Banbury, UK \\ ${ }^{5}$ Department of Obstetrics and Gynecology, University \\ of Rostock, Klinikum Südstadt, Germany
}

\begin{abstract} biometrics. abortions. Maternal age was adjusted for. the control group $(P<0.0001)$.

\footnotetext{
${ }^{*}$ Corresponding author:

PD Dr. Dr. rer. med. habil. Manfred Voigt

Department of Obstetrics and Gynecology

Ernst-Moritz-Arndt University of Greifswald

Wollweberstrasse 1-3

17475 Greifswald

Germany

E-mail: manfred.voigt@kliniksued-rostock.de
}

Objective: To determine whether a history of terminations of pregnancy influences subsequent pregnancies in terms of pregnancy risks, prematurity and neonatal

Patients and methods: Based on the perinatal statistics of eight German federal states, data of 247,593 primiparous women with singleton pregnancies born between 1998 and 2000 were analyzed. The control group consisted of primiparous women without previous induced

Results: There was an overall trend towards an increased rate of preterm delivery at $\leq 36$ weeks' gestation and early preterm delivery at $\leq 31$ weeks' gestation in women who had previous pregnancy terminations. For the cohort of 28-30 years, the observed rates of prematurity in women with one and with $\geq 2$ previous induced abortions were $7.8 \%$ and $8.5 \%$, respectively, compared to $6.5 \%$ in the control population $(P=0.015)$. Preceding terminations of pregnancy did not alter the rate of small-for-gestational-age newborns. Psychosocial stress and symptoms associated with prematurity such as cervical incompetence and vaginal bleeding before and after 28 weeks of gestation occurred more frequently in women with previous induced abortion compared to

Conclusion: The rate of preterm births increases with the number of preceding abortions. Similarly, symptoms associated with prematurity are more common. The rate of small-for-gestational-age newborns was not affected by preceding terminations of pregnancy.

Keywords: Induced abortion; preterm birth; risks of pregnancy; small-for-gestational-age status.

\section{Introduction}

The influence of induced abortions on subsequent pregnancies has been debated for several decades. A relationship between terminations of pregnancy and subsequent ectopic pregnancies [10] is not supported by recent studies $[2,13,14]$. An increase in the rate of premature deliveries following terminations of pregnancy has been shown in a number of papers $[1,6,8,17,19$, 20]. For example, in a study of 61,753 Danish primiparous women Zhou et al. [17] observed an increased rate of preterm births after 2 abortions (OR 2.66). Other studies, however, find no such relationship [5, 7]. It also seems possible that the relationship between terminations of pregnancy and prematurity is not a causal one and that other factors influence both of them. For example, Papiernik [9] points to an influence of maternal occupation on prematurity in this context. The influence of preceding terminations of pregnancy on the subsequent incidence of low birth weight is likewise unclear $[3,6,18]$.

In view of the above controversies, we investigated whether a history of terminations of pregnancy influences subsequent pregnancies in terms of pregnancy risks, prematurity and neonatal biometrics. We took into account important confounding factors such as age, smoking status, past obstetric history and maternal occupation.

\section{Study population and methods}

We used the perinatal statistics from eight German federal states (Bavaria, Brandenburg, Hamburg, Mecklenburg-Western Pomerania, Lower Saxony, Saxony, Saxony-Anhalt and Thuringia) collected between 1998 and 2000. A total of 247,593 primiparous women were included in our retrospective cohort study (Table 1). Data regarding previous terminations of pregnancy were collected by physician interview at the first consultation (booking visit).

Figure 1 shows the $10^{\text {th }}$ percentile for birth weight by gestational age. We define "small-for-gestational-age" (SGA) infants as those with birth weights below the $10^{\text {th }}$ percentile for gestational age. The Figure also illustrates the concepts of preterm 
Table 1 Number of previous terminations of pregnancy in the total study population and in primiparous women only. Data taken from German perinatal statistics.

\begin{tabular}{|c|c|c|c|c|}
\hline \multirow[t]{2}{*}{$\begin{array}{l}\text { Previous } \\
\text { terminations } \\
\text { of pregnancy }\end{array}$} & \multicolumn{2}{|c|}{ Sum total } & \multicolumn{2}{|c|}{$\begin{array}{l}\text { Primiparous women } \\
\text { (previous live and } \\
\text { stillbirths=0) }\end{array}$} \\
\hline & $\%$ & $n$ & $\%$ & $\mathrm{n}$ \\
\hline 0 & 91.2 & 464,158 & 93.9 & 232,472 \\
\hline 1 & 7.3 & 36,919 & 5.4 & 13,497 \\
\hline 2 & 1.2 & 6187 & 0.6 & 1372 \\
\hline 3 & 0.2 & 1169 & \multirow{2}{*}{0.1} & 197 \\
\hline$\geq 4$ & 0.1 & 493 & & 55 \\
\hline & 100.0 & 508,926 & 100.0 & 247,593 \\
\hline
\end{tabular}

births at $\leq 36$ weeks of gestation and early preterm births at $\leq 31$ weeks of gestation.

Figure 2 shows how the number of induced abortions increases with age. Forty-year-old pregnant women have undergone 1 and $\geq 2$ abortions in $9.8 \%$ and $3.6 \%$ of cases, respectively.

Due to the well-established correlation between terminations of pregnancy on the one hand and spontaneous abortions, stillbirths, and nicotine use on the other, we excluded these confounders in our analysis of gestational duration, biometrical characteristics of the newborn and gestational risks. Likewise, ectopic pregnancies in the past medical history led to exclusion from this study. Table 2 provides an overview of the average age, proportion of smokers and incidence of spontaneous abortions and ectopic pregnancies according to the number of previous terminations of pregnancy.
With regard to a possible influence of previous terminations of pregnancy the following parameters were analyzed:

Duration of pregnancy: preterm birth ( $\leq 36$ weeks of gestation), early preterm birth ( $\leq 31$ weeks of gestation).

Somatometrics of the newborn: rates of small-for-gestational-age (SGA) status, appropriate-for-gestational-age (AGA) status and large-for-gestational-age (LGA) status were determined on the basis of the $10^{\text {th }}$ and $90^{\text {th }}$ birth weight percentiles (according to gestational age).

Complications during pregnancy: vaginal bleeding before and after 28 weeks of gestation, cervical incompetence.

The $\chi^{2}$-test was used to establish statistical significance. SPSS was used for data analysis.

\section{Results}

\section{Duration of pregnancy, preterm birth, early preterm birth}

Figure 3 shows the duration of pregnancy, firstly for all primiparous women and secondly after adjustment for age and exclusion of confounders. A trend towards preterm and early preterm birth in women who have previously undergone terminations is visible in all age groups. The results were significantly different for the age group 28-30 years $(P=0.015)$.

The obtained rates of prematurity in primiparous women with previous terminations of pregnancy were analyzed further, taking into consideration maternal occupation. Such an approach was necessary because of the well-established relationship between maternal occupation and rates of preterm birth [9]. Maternal occu-

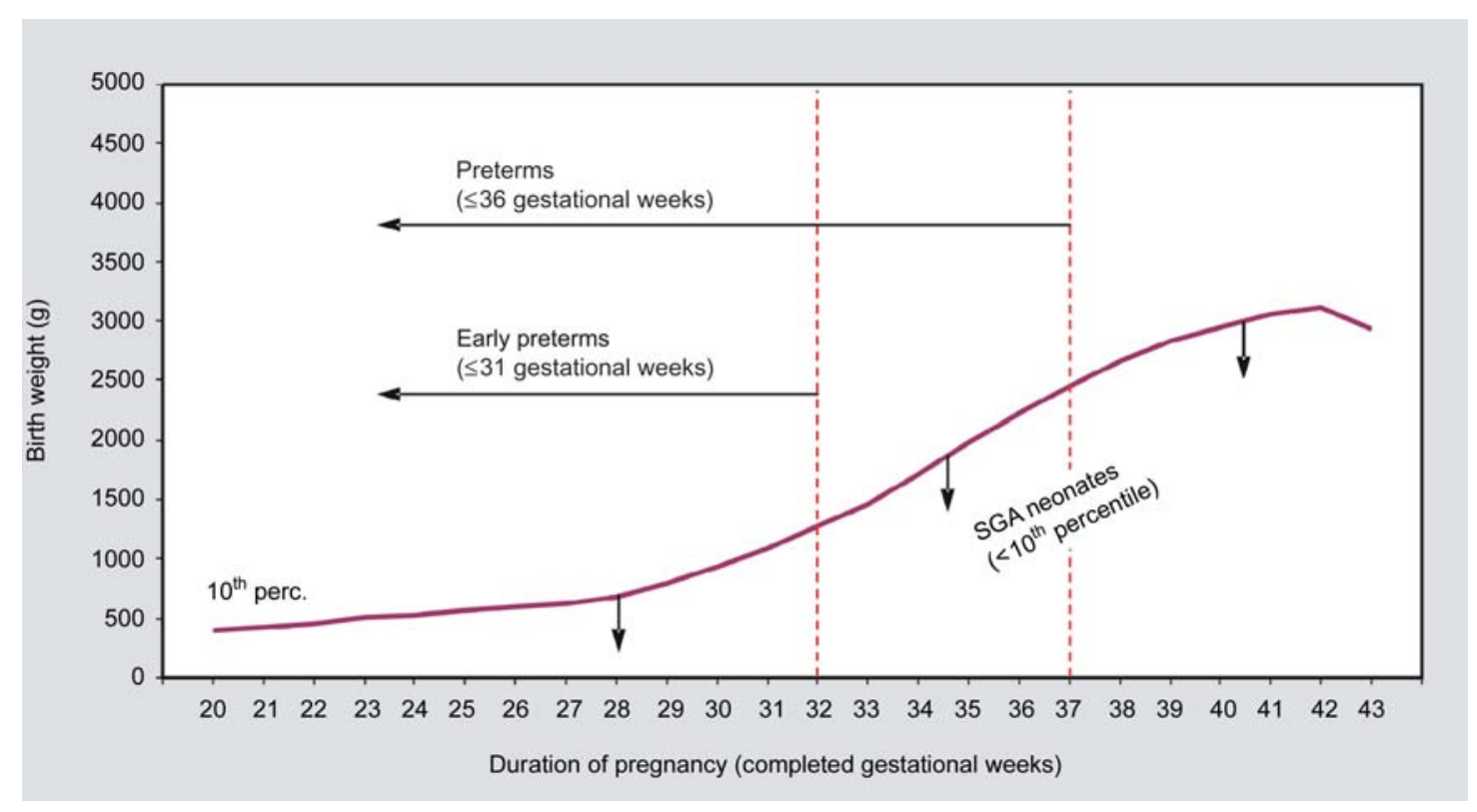

Figure 1 The $10^{\text {th }}$ birth weight percentile according to gestational age and the classification of small-for-gestational-age (SGA) and preterm neonates. 


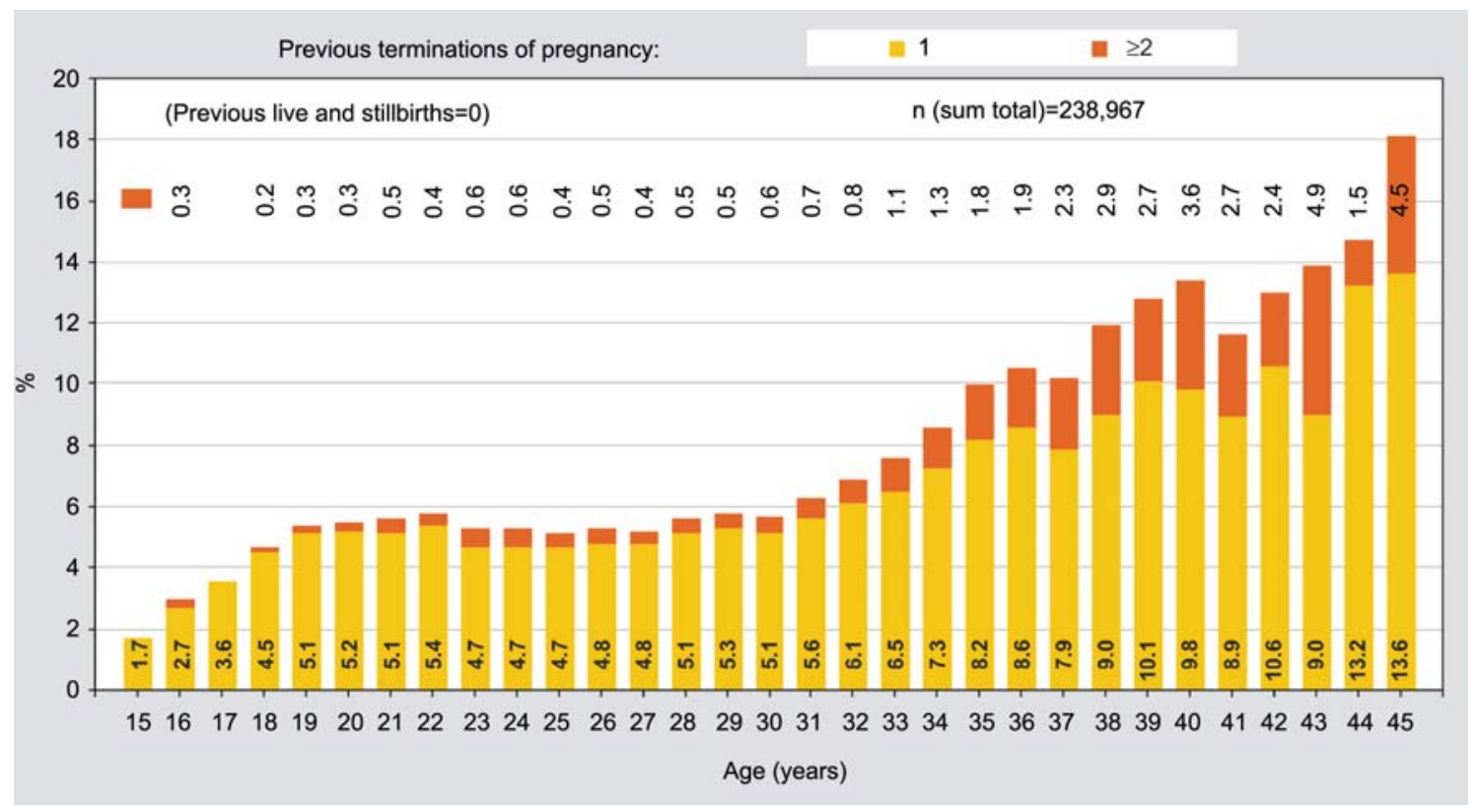

Figure 2 Cases with previous terminations of pregnancy (\% of all primiparous women) according to the age of the primiparous women.

Table 2 Average age, proportion of smokers, number of previous spontaneous miscarriages and ectopic pregnancies in primiparous women according to number of previous terminations of pregnancy.

\begin{tabular}{|l|r|r|r|}
\hline Detail & \multicolumn{4}{|c|}{$\begin{array}{l}\text { Previous terminations of } \\
\text { pregnancy }\end{array}$} \\
\cline { 2 - 4 } & \multicolumn{1}{|c|}{0} & \multicolumn{1}{c|}{1} & \multicolumn{1}{c|}{$\geq 2$} \\
\hline Age (years) & 26.8 & 27.6 & 29.7 \\
\hline Smoker (\%) & 14.9 & 22.7 & 28.7 \\
\hline Previous miscarriages (\%) & 10.9 & 12.8 & 14.8 \\
\hline Previous ectopic pregnancies (\%) & 0.8 & 1.1 & 1.1 \\
\hline \hline
\end{tabular}

pation is classified according to different occupational categories ("housewife", "in training", "on welfare benefits", "skilled worker", "highly qualified skilled worker") in German perinatal statistics. Independent of occupation, the observed trend towards preterm births in women with previous terminations of pregnancy persisted, however it was not statistically significant in all the occupational groups (data not shown).

\section{Classification of the newborns according to birth weight}

Previous terminations of pregnancy did not result in a higher rate of SGA neonates (Figure 4).

\section{Pregnancy risks}

According to our analysis of frequency distributions prior to and after exclusion of confounders, psychosocial stress and symptoms associated with prematurity, such as cervical incompetence and vaginal bleeding before and after 28 weeks of gestation, were more common in women with previous induced abortions (Table 3).

\section{Discussion}

There is an ongoing debate in the literature concerning the relationship between the rate of preterm births and previous termination of pregnancy $[1,4-9,11,12,17$, $19,20]$. Our results show that terminations of pregnancy lead to a slight increase in the rate of preterm births in subsequent pregnancies. The result becomes statistically significant for the cohort of 28-30-year-old women $(P=0.015)$. The rate of preterm births increases with the number of previous terminations of pregnancy. However, in comparison with previous spontaneous abortions and stillbirths, previous terminations of pregnancy have a lesser impact on the rate of preterm births [16]. In agreement with earlier work [6], our results did not find a correlation between previous termination of pregnancy and intrauterine growth retardation.

We believe that the major strength of our study is the large number of subjects investigated - allowing conclusions to be drawn with a high level of confidence. There are also some limitations of our approach, however. Firstly, there are potential errors associated with data collection. Some women might deliberately make inaccurate statements regarding previous terminations, perhaps out of a perceived stigma associated with having had terminations. We feel that this is unlikely to be very common, though, because the data were collected by 


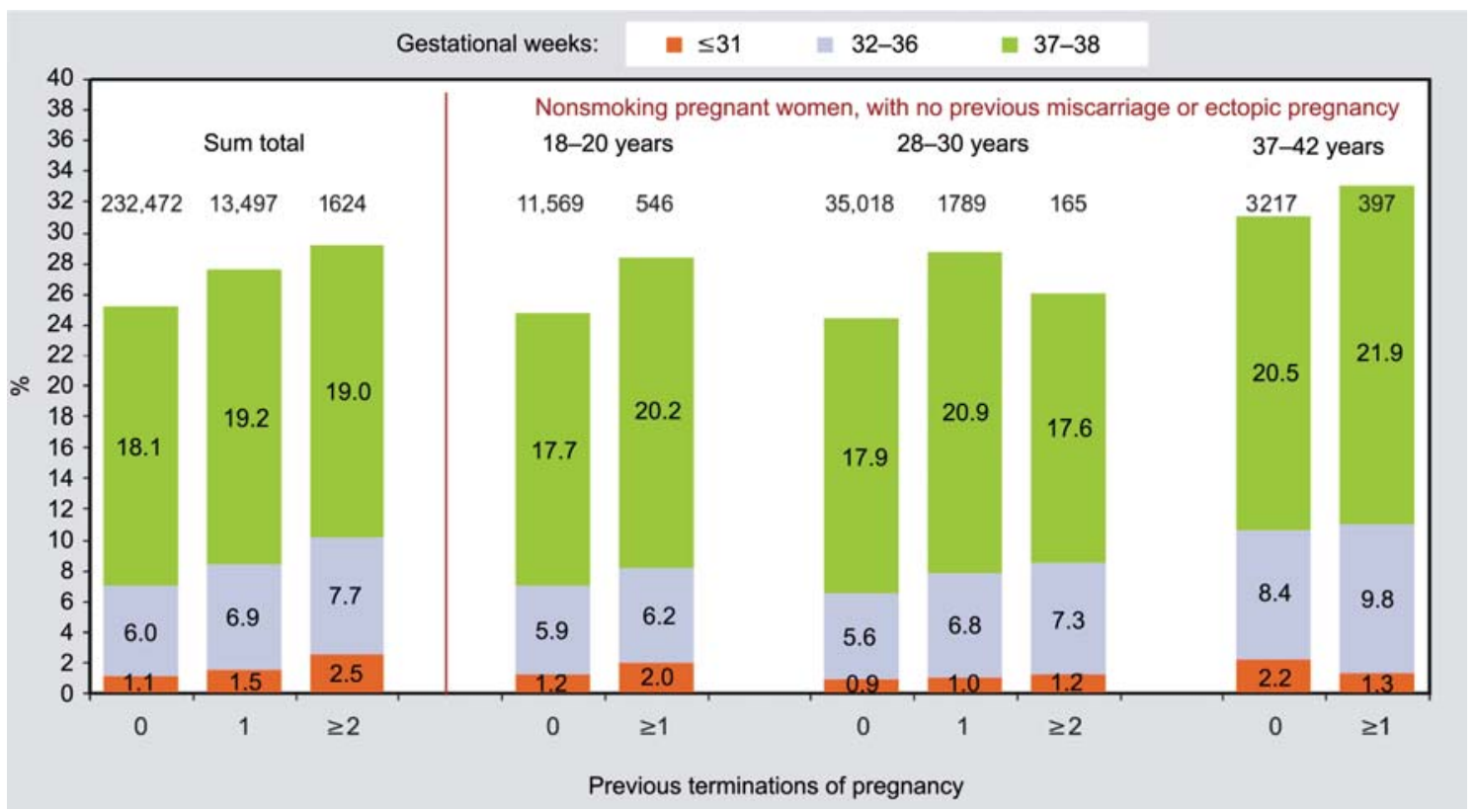

Figure 3 Duration of pregnancy according to the number of previous terminations of pregnancy in primiparous women. Durations of pregnancy of 38 weeks and less (see inset for categories) are shown as \% of all pregnancies in primiparous women. Durations of pregnancy of more that 38 weeks are not shown in the Figure. They make up the rest of the cases.

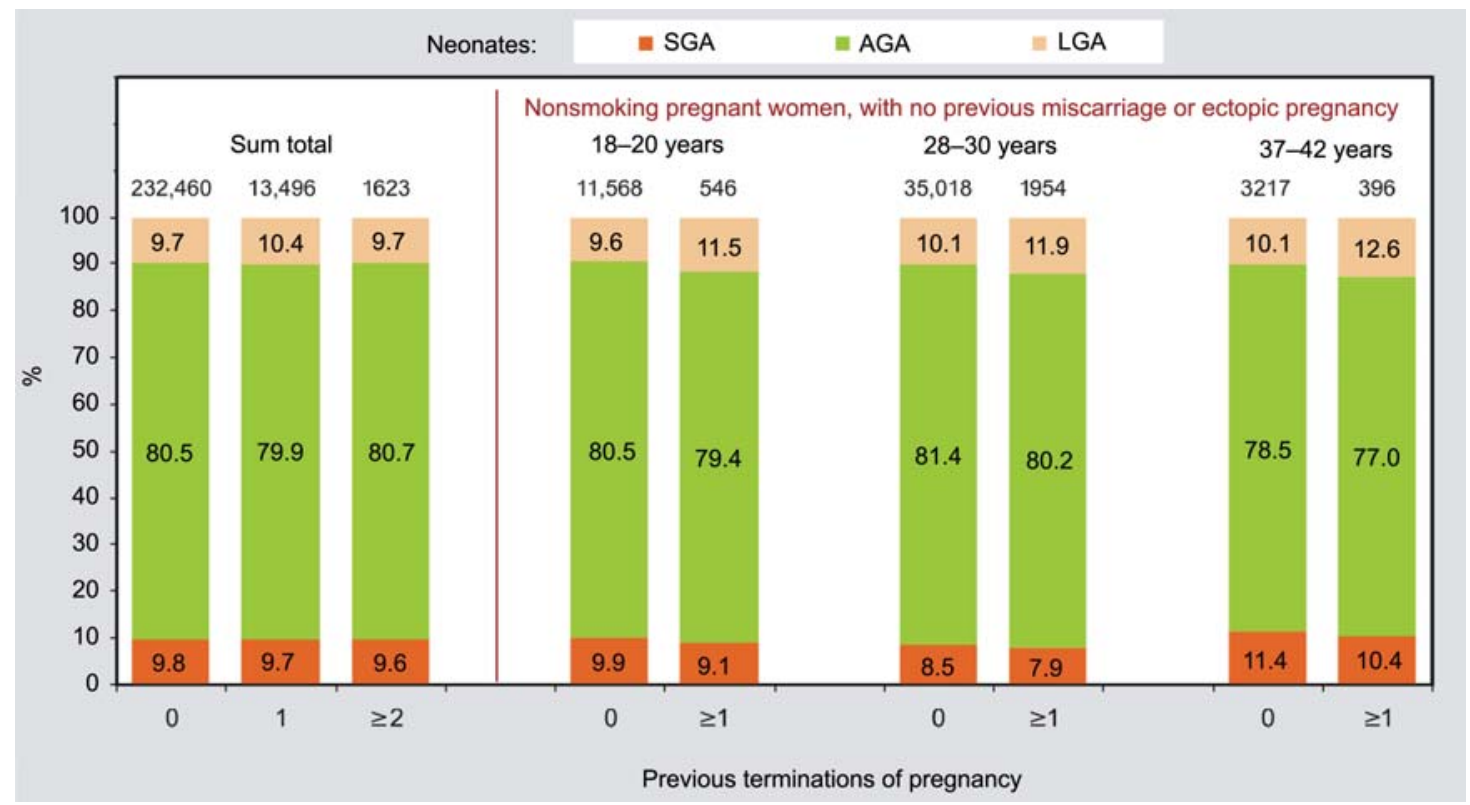

Figure 4 Terminations of pregnancy and somatic classification of neonates born to primiparous mothers (SGA, AGA, LGA). See "study population and methods" section for definitions.

physician interview. Women have an interest in receiving optimal medical care and are therefore likely to report their past obstetric history accurately to their physician. Secondly, we could not differentiate between different indications for a termination of pregnancy and between different methods of termination (surgical vs. medical). However, a recent study found no significant differences between medical and surgical methods with regard to a range of subsequent adverse pregnancy outcomes [15]. Thirdly, the perinatal statistics that form the basis of our analysis do not include pregnancies that miscarry so early that the women were never seen by a physician. Fourthly, our data did not allow us to analyze the interval between terminations and subsequent pregnancies. 
Table 3 Common pregnancy risks and their relation to previous terminations of pregnancy.

\begin{tabular}{|c|c|c|c|c|c|c|c|c|c|c|}
\hline \multicolumn{2}{|c|}{ Pregnancy risks } & \multicolumn{9}{|c|}{ Previous terminations of pregnancy } \\
\hline & & 0 & 1 & $\geq 2$ & 0 & $\geq 1$ & 0 & $\geq 1$ & 0 & $\geq 1$ \\
\hline & & \multicolumn{3}{|c|}{ Primiparae (sum total) } & \multicolumn{2}{|c|}{$18-20$ years } & \multicolumn{2}{|c|}{$28-30$ years } & \multicolumn{2}{|c|}{$37-42$ years } \\
\hline & Psychological distress & $\begin{array}{l}2.9 \\
6651\end{array}$ & $\begin{array}{l}3.8 \\
513\end{array}$ & $\begin{array}{l}4.4 \\
71\end{array}$ & $\begin{array}{l}6.1 \\
703\end{array}$ & $\begin{array}{l}7.3 \\
40\end{array}$ & $\begin{array}{l}1.6 \\
551\end{array}$ & $\begin{array}{l}2.7 \\
53\end{array}$ & $\begin{array}{l}2.6 \\
85\end{array}$ & $\begin{array}{l}3.0 \\
12\end{array}$ \\
\hline 07 & Social distress & $\begin{array}{l}2.7 \\
6344\end{array}$ & $\begin{array}{l}3.5 \\
475\end{array}$ & $\begin{array}{l}4.4 \\
71\end{array}$ & $\begin{array}{l}8.9 \\
1030\end{array}$ & $\begin{array}{l}10.3 \\
56\end{array}$ & $\begin{array}{l}0.9 \\
325\end{array}$ & $\begin{array}{l}1.9 \\
38\end{array}$ & $\begin{array}{l}1.1 \\
36\end{array}$ & $\begin{array}{l}1.5 \\
6\end{array}$ \\
\hline 32 & Vaginal bleeding before 28 wk's* & $\begin{array}{l}2.6 \\
6113\end{array}$ & $\begin{array}{l}3.6 \\
486\end{array}$ & $\begin{array}{l}3.3 \\
54\end{array}$ & $\begin{array}{l}2.0 \\
231\end{array}$ & $\begin{array}{l}2.9 \\
16\end{array}$ & $\begin{array}{l}2.7 \\
955\end{array}$ & $\begin{array}{l}3.5 \\
69\end{array}$ & $\begin{array}{l}2.5 \\
80\end{array}$ & $\begin{array}{l}3.3 \\
13\end{array}$ \\
\hline 33 & Vaginal bleeding after 28 wk's* & $\begin{array}{l}0.7 \\
1555\end{array}$ & $\begin{array}{l}1.0 \\
132\end{array}$ & $\begin{array}{l}0.9 \\
14\end{array}$ & $\begin{array}{r}0.6 \\
66\end{array}$ & $\begin{array}{l}1.1 \\
6\end{array}$ & $\begin{array}{l}0.7 \\
260\end{array}$ & $\begin{array}{l}0.6 \\
11\end{array}$ & $\begin{array}{l}0.8 \\
25\end{array}$ & $\begin{array}{l}2.0 \\
8\end{array}$ \\
\hline & Cervical incompetence & $\begin{array}{l}2.7 \\
6167\end{array}$ & $\begin{array}{l}3.3 \\
443\end{array}$ & $\begin{array}{l}3.6 \\
59\end{array}$ & $\begin{array}{r}3.9 \\
449\end{array}$ & $\begin{array}{l}5.1 \\
28\end{array}$ & $\begin{array}{l}2.3 \\
799\end{array}$ & $\begin{array}{l}2.6 \\
51\end{array}$ & $\begin{array}{l}2.1 \\
69\end{array}$ & $\begin{array}{l}2.0 \\
8\end{array}$ \\
\hline
\end{tabular}

Finally, with regard to premature deliveries we could not differentiate between spontaneous preterm labor and induction of labor for medical indications.

Although all the limitations of our study have to be considered, we nonetheless think that important conclusions can be drawn from our analysis: termination of pregnancy needs to be regarded as a risk factor for preterm birth in a subsequent pregnancy. The risk of preterm birth increases with the number of previous induced abortions. An increase in the rate of SGA newborns as a consequence of a preceding termination of pregnancy could not be demonstrated.

\section{References}

[1] Ancel PY, Lelong N, Papiernik E, Saurel-Cubizolles MJ, Kaminski M, EUROPOP. History of induced abortion as a risk factor for preterm birth in European countries: results of the EUROPOP survey. Hum Reprod. 2004;19:734-40.

[2] Atrash HK, Strauss LT, Kendrick JS, Skjeldestad FE, Ahn YW. The relation between induced abortion and ectopic pregnancy. Obstet Gynec. 1997;89:512-8.

[3] Bracken MB, Hellenbrand KG, Holford TR, Bryce-Buchanan $C$. Low birth weight in pregnancies following induced abortion: no evidence for an association. Am J Epidemiol. 1986;123:604-13.

[4] Che Y, Zhou W, Gao E, Olsen J. Induced abortion and prematurity in a subsequent pregnancy: a study from Shanghai. J Obstet Gynaec. 2001;21:270-3.

[5] Chen A, Yuan W, Meirik O, Wang X, Wu SZ, Zhou L, et al. Mifepristone-induced early abortion and outcome of subsequent wanted pregnancy. Am J Epidemiol. 2004;160: $110-7$.
[6] Henriet L, Kaminski M. Impact of induced abortions on subsequent pregnancy outcome: the 1995 French national perinatal survey. Br J Obstet Gynaecol. 2001;108:103642.

[7] Lao TT, Ho LF. Induced abortion is not a cause of subsequent preterm delivery in teenage pregnancies. Hum Reprod. 1998;13:758-61.

[8] Moreau C, Kaminski M, Ancel PY, Bouyer J, Escande B, Thiriez G, et al. Previous induced abortions and the risk of very preterm delivery: results of the EPIPAGE study. $\mathrm{Br} \mathrm{J}$ Obstet Gynaecol. 2005;112:430-7.

[9] Papiernik E. Is the high rate of preterm birth in the United States linked to previous induced abortions? Pediatrics. 2006;118:795-6.

[10] Parazzini F, Ferraroni M, Tozzi L, Ricci E, Mezzopane R, La Vecchia C. Induced abortions and risk of ectopic pregnancy. Hum Reprod. 1995;10:1841-4.

[11] Raatikainen K, Heiskanen N, Heinonen S. Induced abortion: not an independent risk factor for pregnancy outcome, but a challenge for health counseling. Ann Epidem. 2006;16:587-92.

[12] Rooney B, Calhoun BC. Induced abortion and risk of later premature births. Am Phys Surg. 2003;8:46-9.

[13] Skjeldestad FE, Atrash HK. Evaluation of induced abortion as a risk factor for ectopic pregnancy. A case-control study. Acta Obstet Gynecol Scand. 1997;76:151-8.

[14] Skjeldestad FE, Gargiullo PM, Kendrick JS. Multiple induced abortions as risk factor for ectopic pregnancy. A prospective study. Acta Obstet Gynecol Scand. 1997;76: 691-6.

[15] Virk J, Zhang J, Olsen J. Medical abortion and the risk of subsequent adverse pregnancy outcomes. New Engl J Med. 2007;357:648-53.

[16] Voigt M, Olbertz D, Fusch C, Krafczyk D, Briese V, Schneider KTM. The influence of previous pregnancy terminations, miscarriages and still-births on the incidence of babies with low birth weight and premature births as well 
as a somatic classification of newborns. Z Geburtsh Neonatol. 2008;212:5-12.

[17] Zhou W, Sorensen HT, Olsen J. Induced abortion and subsequent pregnancy duration. Obstet Gynecol. 1999;94: 948-53.

[18] Zhou W, Sorensen HT, Olsen J. Induced abortion and low birth weight in the following pregnancy. Int $\mathrm{J}$ Epidemiol. 2000;29:100-6.

[19] Zwahr C, Voigt M. The effect of various parameters on the incidence of premature births. Zentralbl Gynakol. 1983; 105:1307-12.
[20] Zwahr C, Neubert D, Triebel U, Voigt M, Knüppel KH. Correlation between some environmental, anamnestic and social markers of pregnant patients and the delivery of eutrophic premature and hypotrophic newborn infants. Zentralbl Gynakol. 1988;110:479-87.

Received April 21, 2008. Revised July 2, 2008. Accepted July 25, 2008. Previously published online October 31, 2008. 